Research Article

\title{
Evaluation of WeMedia Ads Marketing Based on the Demand of Internet Economy
}

\author{
Zhuo Bian \\ Art Academy of Northeast Agriculture University, Harbin 150001, China \\ Correspondence should be addressed to Zhuo Bian; bianzhuo1219@126.com
}

Received 16 June 2021; Revised 9 July 2021; Accepted 12 July 2021; Published 20 July 2021

Academic Editor: Daqing Gong

Copyright (C) 2021 Zhuo Bian. This is an open access article distributed under the Creative Commons Attribution License, which permits unrestricted use, distribution, and reproduction in any medium, provided the original work is properly cited.

\begin{abstract}
To fully understand the root causes for consumer's trust and preference of we-media marketing, it is important to explore deep into the features and superiorities of the marketing model of we-media marketing platforms, as well as the factors affecting the profit-making of the model. The existing studies on WeMedia ads marketing at home and abroad are mostly descriptive analysis on the relevant concepts, the importance of WeMedia ads marketing, product quality monitoring, and the reasonability of marketing models. There is a lack of quantitative results on deeper layers. To make up for the gap, this paper explores the evaluation of WeMedia ads marketing based on the demand of Internet economy. Firstly, an evaluation index system (EIS) was established for WeMedia ads marketing, and the weight of each index was determined in turn. Then, the authors created an evaluation model, carried out the corresponding confirmatory factor analysis (CFA), and verified the model through the degree of fit verification. Experimental results confirm the correctness and effectiveness of the constructed model. The results provide a reference for the evaluation of other marketing models.
\end{abstract}

\section{Introduction}

In the context of Internet economy, online trading platforms provide numerous small businesses with entrepreneurial and employment opportunities and offer convenient consumption approaches and choices to all citizens [1-5]. As an indispensable part of the modern market economy, the WeMedia marketing channels (e.g., live broadcast, WeChat, forums, short videos, and Weibo) on Chinese online e-commerce platforms achieved a turnover of more than 100 billion yuan [6-10]. To find the root causes for consumers' trust and preference for WeMedia marketing, it is important to deeply explore the features, merits, and profit factors of the marketing model of WeMedia marketing platforms. The exploration results help to propose countermeasures that update and optimize the marketing model for better profit and performance.

To adapt to the latest trend of the market pattern, each brand needs to rely on the new model of WeMedia marketing to expand the audience and look for new ideas and growth points for product sales [11-17]. Based on the theories of online marketing and online opinion leaders, Kollintza-Kyriakoulia et al. [18] determined the evaluation indices for the performance of the trendy live broadcast marketing and constructed a system of 24 indices in five aspects, namely, marketing amount, after-sale service, marketing value, platform performance, and social benefit. To help policymakers and media platform operators promote the development of online media industry, Kim [19] demonstrated the influence of three factors, namely, matching technology, consumer strategy, and advertising technology, on network scale and social welfare and provided helpful suggestions on how to prevent media platform operators from abusing their power. Wang and Gao [20] deeply analyzed the inadequacies of WeChat WeMedia marketing models in precision marketing, brand perception, and interestingness through questionnaire survey and indepth interview and discussed the relationship between WeChat WeMedia platform, consumers, suppliers, and advertisers.

WeMedia differs greatly from the traditional media in the marketing model. To make more profits, it is necessary to 
sort out and summarize the features, functions, and development levels of WeMedia ads marketing [21-26]. Chen et al. [27] detailed the connotations of integrated marketing communication theory, combined the theory with WeMedia ads marketing, and modeled the factors affecting the consumption willingness under WeMedia ads marketing. Brekke and Nilssen [28] carried out a mathematical analysis on the consumption data under WeMedia ads marketing, compared the results of the analysis with those obtained by the theoretical model, and concluded that WeMedia ads marketing strategies affect the marketing channels and contents in four dimensions: interestingness, interactivity, practicality, and economic benefits. Taking short video WeMedia as the objects, Mujahid [29] reviewed the impact of green WeMedia marketing on the organizational performance of small enterprises and discussed how the integration of learning orientation in organization's internal culture determines the influence of green strategies on corporate value improvement.

The existing studies at home and abroad rarely quantify WeMedia ads marketing. Rather, most of them are descriptive analyses on the relevant concepts, the importance of WeMedia ads marketing, product quality monitoring, and the reasonability of marketing models. There is a lack of quantitative results on deeper layers. To make up for the gap, this paper attempts to evaluate WeMedia ads marketing based on the demand of Internet economy. The main contents of this work are as follows: setting up a detailed evaluation index system (EIS) [30-32] for WeMedia ads marketing, which covers three aspects: online marketing performance, supplier performance, and relationship benefit; determining the weight of each evaluation index through multilevel fuzzy comprehensive evaluation (FCE) [33]; building effect evaluation models and performing confirmatory factor analysis (CFA) [34]; and verifying the effect evaluation models by fitness test and proving the correctness and effectiveness of the model through experiments.

Starting with the online transactions in the context of the development of the Internet economy, this paper discusses the influence of we-media on ad marketing performance, with the aim of laying the basis for decision-making of small merchants facing the demand of the Internet economy, as well as small and medium-sized enterprises amidst the everchanging we-media marketing landscape. The research also attempts to provide a reference for industry-wide we-media marketing.

\section{EIS Construction}

The EIS for WeMedia ads marketing should be constructed by the specific-measurable-achievable-relevant-time-bound (SMART) principle. To realize the goals, this principle must be adhered to throughout the design of the performance evaluation indices for WeMedia ads marketing, making the EIS more reasonable and effective. Drawing on the literature and theories on Internet economy, this paper sets up an effective EIS for small merchants as well as small and medium-sized enterprises, which implement WeMedia ads marketing. Covering three primary aspects (i.e., online marketing performance, supplier performance, and relationship benefit), the EIS paves the way for the subsequent expert survey, factor analysis, and model construction.

The EIS covers three main dimensions, namely, online marketing performance, supplier performance, and relationship benefit. Based on the demand of Internet economy, the EIS for WeMedia ads marketing should reflect the effect, economic benefit, and social benefit of the current marketing model and be quantifiable, available, and representative. Under these guidelines, the specific EIS was constructed as follows:

Layer 1 (primary indices):

$M P=\left\{M P_{1}, M P_{2}, M P_{3}\right\}=\{$ online marketing performance, supplier performance, relationship benefit $\}$

Layer 2 (secondary indices):

$M P_{1}=\left\{M P_{11}, M P_{12}\right\}=\{$ online operation performance, online marketing value $\}$

$M P_{2}=\left\{M P_{21}, \quad M P_{22}\right\}=\{$ supplier sales performance, consumer source concentration, after-sale service $\}$

$M P_{3}=\left\{M P_{31}, M P_{32}\right\}=\{$ consumer relationship benefit, enterprise participation $\}$

Layer 3 (tertiary indices):

$M P_{11}=\left\{M P_{111}, M P_{112}, M P_{113}, M P_{114}\right\}=\{$ commodity repurchase rate, number of readers or viewers, percapita reading or viewing time, number of consultations\}

$M P_{12}=\left\{M P_{121}, M P_{112}, M P_{123}\right\}=\{$ WeMedia exposure, mainstream media exposure, online search frequency $\}$ $M P_{21}=\left\{M P_{211}, M P_{212}, M P_{213}, M P_{214}\right\}==\{$ sales volume, sales amount, sales volume growth rate, sales amount growth rate\}

$M P_{22}=\left\{M P_{221}, M P_{222}, M P_{223}\right\}=\{$ number of source regions, maximum regional sales, minimum regional sales\}

$M P_{23}=\left\{M P_{231}, M P_{232}, M P_{233}, M P_{234}\right\}=\{$ return or refund rate, positive review rate, logistics time, afterservice evaluation

$M P_{31}=\left\{M P_{311}, M P_{312}, M P_{313}, M P_{314}\right\}==$ number of reviews, number of sharing, number of likes, number of forwarding $\}$

$M P_{32}=\left\{M P_{321}, M P_{322}\right\}=\{$ number of online operators, number of suppliers

In terms of online operation performance, commodity repurchase rate $M P_{111}$ refers to the proportion of consumers who have made more than two purchases; the number of readers or viewers $M P_{112}$ refers to the number of consumers who have read the pushed articles or viewed videos and live broadcasts; per-capita reading or viewing time $M P_{113}$ refers to the mean duration of consumers staying on the pages of articles, videos, and live broadcasts; and the number of 
consultations $M P_{114}$ refers to the number of windows that pop up as consumers query after-service staff.

In terms of online marketing value, WeMedia exposure $M P_{121}$ refers to the number of exposures on top search; mainstream media exposure $M P_{122}$ refers to the number of exposures on media above the provincial level; and online search frequency $M P_{123}$ refers to the online trend index.

In terms of supplier sales performance, sales volume $M P_{211}$ refers to the number of purchased commodities; sales volume growth rate $M P_{212}$ is calculated by (the number of sold commodities in the current month/that in the previous month-1) $\times 100 \%$; sales amount $M P_{213}$ refers to the specific turnover; and sales amount growth rate $M P_{214}$ is calculated by (the sales volume in the current month/that in the previous month -1$) \times 100 \%$.

In terms of consumer source concentration, the number of source regions $M P_{221}$ refers to the number of cities for order placement; maximum regional sales $M P_{222}$ refers to the highest sales among all consumer markets; and minimum regional sales $M P_{223}$ refers to the lowest sales among all consumer markets.

In terms of after-sale service, return or refund rate $M P_{231}$ is calculated by the number of returned commodities, which are sold in the current month/the number of commodities sold in the current month; positive review rate $M P_{232}$ is calculated by the number of positive reviews on the commodities sold in the current month/the number of commodities sold in the current month; logistics time $M P_{233}$ refers to the mean duration from shipment to reception; and after-service evaluation $M P_{234}$ refers to the consumer evaluation of product quality.

In terms of consumer relationship benefit, the number of reviews $M P_{311}$ refers to the number of pushed articles or videos, or live broadcast links being reviewed; the number of sharing $M P_{312}$ refers to the numbers of pushed articles or videos, or live broadcast links being shared; the number of likes $M P_{313}$ refers to the number of pushed articles or videos, or live broadcast links being liked; and the number of forwarding $M P_{314}$ refers to the number of pushed articles or videos, or live broadcast links being forwarded.

In terms of enterprise participation, the number of online operators $M P_{321}$ refers to the number of online operators that engage in ads marketing through pushing articles or videos, or live broadcasting, and the number of suppliers $M P_{322}$ refers to the number of suppliers that engage in ads marketing.

\section{Multilevel FCE Model}

Through the analytic hierarchy process (AHP) $[35,36]$, this paper determines the weight of each evaluation index for WeMedia ads marketing. Based on the demand of Internet economy, the complex problem of WeMedia ads marketing was interpreted and parsed to reveal the correlations between all the influencing factors. Then, these factors were divided into multiple classes by the evaluation objectives. Each class contains many evaluation criteria. In this way, a model of clear hierarchy was established based on the above EIS.
After obtaining a complete, scientific, and quantifiable model, experts were invited to weigh and rate the importance of each index on a layer relative to each index on the superior layer, according to the judgement matrix formed through pairwise comparison between indices. The ratings reflect the relative importance between indices on the same layer. In the judgement matrix, each element $e_{a b}$ represents the quantified value of the relative importance between indices $M P_{a}$ and $M P_{b}$ on the same layer.

To assign accurate weights to indices, the first step is to normalize the elements in the judgement matrix $E$. The general term of the element $e_{a b}$ in the $a$-th row and $b$-th column can be described as

$$
e_{a b}^{\prime}=\frac{e_{a b}}{\sum_{a=1}^{M} e_{a b}}, \quad(a, b=1,2, \ldots, M)
$$

where $e_{a b}$ belongs to the interval of $[0,1]$. After normalization, the elements in $E$ can be added by rows:

$$
G_{a}^{\prime}=\sum_{a=1}^{M} e_{a b}^{\prime}, \quad(a=1,2, \ldots, M) .
$$

The eigenvector $G^{\prime}=\left(G_{1}^{\prime}, G_{2}^{\prime}, \ldots, G_{M}^{\prime}\right)^{T}$ of evaluation indices can be normalized by

$$
G_{a}=\frac{G_{a}^{\prime}}{\sum_{a=1}^{M} G^{\prime}}, \quad(a=1,2, \ldots, M) .
$$

The approximate solution of the eigenvector is the normalized result $G\left(G_{1}, G_{2}, \ldots, G_{M}\right)^{T}$ obtained by formula (3). Let $(E \cdot G)_{a}$ be the $a$-th element in the matrix formed by multiplying the judgement matrix $E$ with the eigenvector $G$. Then, the maximum characteristic root of $E$ can be calculated by

$$
\mu_{\max }=\sum_{a=1}^{M} \frac{(E \cdot G)_{a}}{M \cdot G_{a}} .
$$

To obtain scientific and reasonable evaluation results of WeMedia ads marketing, the consistency of the judgement matrix $E$ should be tested, using the consistency index $\delta$ :

$$
\delta=\frac{\mu_{\max }-M}{M-1} .
$$

The mean random consistency index $\xi$ of the judgement matrix $E$ can be obtained by looking up the table. The random consistency ratio $\eta$ can be obtained by dividing $\delta$ with $\xi$ of the same order:

$$
\begin{array}{r}
\mathrm{CR}=\frac{\mathrm{CI}}{\mathrm{RI}}, \\
\eta=\frac{\delta}{\xi} .
\end{array}
$$

If $\eta>0.1$, then the elements in matrix $E$ are highly inconsistent. The matrix should be adjusted and updated to achieve a satisfactory consistency. If $\eta<0.1$, then the elements in matrix $E$ are highly consistent. The weight vectors can be equivalent to normalized eigenvectors. 
After the judgement matrix is prepared through pairwise comparison between indices, it is necessary to evaluate the relative importance between two indices on the same layer. $N$ experts on Internet economy and WeMedia ads marketing were invited to fill out a questionnaire. The questions are about the analysis, weighing, and rating of the importance of each index on a layer relative to each index on the superior layer.

The valid questionnaires filled out by $20-30$ experts were analyzed on the comprehensive evaluation assistance software YAAHP. Firstly, the proposed EIS was entered into the "Establishing Hierarchical Model" interface of YAAHP. Then, the names, ages, majors, and titles of the $N$ experts were imported by the "Group Decision" in the "Judgement Matrix" interface, and the weights of the experts were set to $1 / N$. By importing the data on the questionnaires filled out by the experts, the judgement matrix was updated according to the opinions of the experts. After the data of $N$ experts had been imported, the random consistency ratios $\eta$ were obtained for the $\mathrm{N}$ judgement matrices. If some or all $\eta$ values are greater than 0.1 , then the $N$ judgement matrices are highly inconsistent; if all $\eta$ values are smaller than 0.1 , then the $N$ judgement matrices are of satisfactory consistency.

Finally, the "Group Decision Results" was selected in the option "Weighted Geometric Average" to obtain the weights of all indices for WeMedia ads marketing. Then, the weights of primary, secondary, and tertiary indices were denoted as $M P_{a}(a=1,2, \ldots, q), M P_{a b}(a=1,2, \ldots, q ; b=1,2, \ldots, N)$, and $M P_{a b l}(a=1,2, \ldots, q ; b=1,2, \ldots, N ; l=1,2, \ldots, M)$, respectively.

The proposed EIS contains both quantitative and qualitative indices. According to the above judgement criteria for the goodness of WeMedia ads marketing evaluation, the qualitative indices were divided into five levels: strongly good, good, normal, bad, and strongly bad. The evaluation criteria of quantitative indices were further defined by the FCE.

3.1. Three-Level FCE. Firstly, $M P_{a b l}(a=1,2, \ldots, q ; b=1,2$, $\ldots, N ; l=1,2, \ldots, M)$ was combined with the FCE matrix $E_{a b}$ $(a=1,2, \ldots, q ; b=1,2, \ldots, N)$ composed of $E_{a b l}$ to obtain the evaluation results of tertiary indices $\theta_{a b}(a=1,2, \ldots, q ; b=1$, $2, \ldots, N)$. When $a$ and $b$ are minimized, $\theta_{a b}$ can be calculated by

$$
\theta_{11}\left(M P_{111}, M P_{112}, \ldots, M P_{11 M}\right) \otimes\left[\begin{array}{c}
E_{111} \\
E_{112} \\
\ldots \\
E_{11 M}
\end{array}\right] .
$$

When $a$ and $b$ are maximized, $\theta_{a b}$ can be calculated by

$$
\theta_{q N}=\left(M P_{q N 1}, M P_{q N 2}, \ldots, M P_{q N M}\right) \otimes\left[\begin{array}{c}
E_{q N 1} \\
E_{q N 2} \\
\ldots \\
E_{q N M}
\end{array}\right] .
$$

The evaluation results of tertiary indices can be synthetized into the FCE matrix $E_{a}(a=1,2, \ldots, q)$ for secondary indices. When $a$ is minimized, $E_{a}$ can be calculated by

$$
E_{1}=\left[\begin{array}{c}
\theta_{11} \\
\theta_{12} \\
\ldots \\
\theta_{1 M}
\end{array}\right]
$$

When $a$ is maximized, $E_{a}$ can be calculated by

$$
E_{p}=\left[\begin{array}{c}
\theta_{q 1} \\
\theta_{q 2} \\
\ldots \\
\theta_{q M}
\end{array}\right]
$$

3.2. Second-Level FCE. Firstly, $M P_{a b}(a=1,2, \ldots, q ; b=1,2$, $\ldots, N)$ was combined with $E_{a}(a=1,2, \ldots, q)$ to obtain the evaluation results of secondary indices $\theta_{a}(a=1,2, \ldots, q)$. When $a$ is minimized, $\theta_{a}$ can be calculated by

$$
\theta_{1}=\left(M P_{11}, M P_{12}, \ldots, M P_{1 N}\right) \otimes\left[\begin{array}{c}
\theta_{11} \\
\theta_{12} \\
\ldots \\
\theta_{1 M}
\end{array}\right] \text {. }
$$

When $a$ is maximized, $\theta_{a}$ can be calculated by

$$
\theta_{q}=\left(M P_{q 1}, M P_{q 2}, \ldots, M P_{q M}\right) \otimes\left[\begin{array}{c}
\theta_{q 1} \\
\theta_{q 2} \\
\ldots \\
\theta_{q M}
\end{array}\right] .
$$

The evaluation results of secondary indices can be synthetized into the FCE matrix $E$ for primary indices, namely, marketing performance, supplier performance, and relationship benefit:

$$
E_{1}=\left[\begin{array}{c}
\theta_{1} \\
\theta_{2} \\
\cdots \\
\theta_{q}
\end{array}\right]
$$

3.3. First-Level FCE. Firstly, $M P=\left(M P_{1}, M P_{2}, \ldots, M P_{q}\right)$ was synthetized with $E$ to obtain the evaluation results of primary indices $\theta=\left(\theta_{1}, \theta_{2}, \ldots, \theta_{q}\right)$, that is, the multilevel FCE results in $\theta$ of WeMedia ads marketing based on the demand of Internet economy: 


$$
\theta=M P \otimes E=\left(M P_{1}, M P_{2}, \ldots, M P_{q}\right) \otimes\left[\begin{array}{c}
\theta_{1} \\
\theta_{2} \\
\ldots \\
\theta_{q}
\end{array}\right]=\left(\lambda_{1}, \lambda_{2}, \ldots, \lambda_{q}\right) .
$$

The $\theta$ value is not a definite value, but a fuzzy vector. Based on the principle of maximum membership, if there exists $\theta_{R}=\max \left(\theta_{1}, \theta_{2}, \ldots, \theta_{q}\right)$, then the elements in the criteria set $U=\left\{U_{1}, U_{2}, \ldots, U_{M}\right\}$ corresponding to $\theta_{R}$ are the final evaluation results of WeMedia ads marketing PE.

\section{Effect Evaluation Modeling and CFA}

4.1. Sample Statistics. To judge whether the questionnaire is valid, the diversity of data was simply analyzed through descriptive statistics. Table 1 shows the descriptions and statistics of online marketing performance ratings. The mean expert ratings on the seven tertiary indices under online operation performance and online marketing value were all greater than 4, indicating that experts all have above the average perception of the indices of online marketing performance. Meanwhile, the standard deviations of the tertiary indices fluctuated around 1, suggesting that the index samples are consistent in terms of oscillation and that the experts are the same in the difference of perception.

Table 2 shows the descriptions and statistics of supplier performance ratings. The mean expert ratings on the seven tertiary indices under supplier sales performance and aftersale service were around 5 , with standard deviations of about 1. It can be inferred that the index samples to a certain extent mirror the supplier performance ratings and the experts differ slightly in perception. However, the mean ratings on consumer source concentration were all smaller than 4 , with standard deviations greater than 1.5. This means the experts poorly perceive consumer source concentration from the index samples and differ greatly in perception.

Similarly, as can be seen from Table 3, under relationship benefit, the mean ratings and standard deviations on consumer relationship benefit and enterprise participation were greater than 4.7 and 1, respectively. Hence, the experts moderately perceive relationship benefit and differ slightly in perceptions.

4.2. CFA. An effect evaluation model was constructed, and the key evaluation criteria were sorted out to further evaluate the degree of influence of the three primary indices (online marketing performance, supplier performance, and relationship benefit) on the WeMedia ads marketing effect based on the demand of Internet economy. Firstly, a second-order plane model was established for the secondary indices under each primary index. Next, a fitness test was conducted to evaluate the correctness of the model. Then, the model was adjusted and optimized to generate more reasonable evaluation results.

The second-order plane model in Figure 1 covers two planes: online operation performance and online marketing value. The evaluations of online marketing performance should be reasonable and necessary for constituting the two planes. Therefore, four pattern analyses were carried out: first-order one-factor analysis, first-order two-factor uncorrelated analysis, first-order two-factor correlated analysis, and second-order factor analysis.

Since the evaluation plane of supplier performance is a two-order plane, supplier performance evaluation was split into three planes, namely, supplier sales performance, consumer source concentration, and after-sale service. The evaluations of supplier performance should be reasonable and necessary for constituting the two planes. Similarly, four pattern analyses were carried out: first-order one-factor analysis, first-order three-factor uncorrelated analysis, firstorder three-factor correlated analysis, and second-order factor analysis (Figure 2).

Figure 3 shows the second-order plane model for relationship benefit. This paper divides relationship benefit evaluation into two planes: consumer relationship benefit and enterprise participation. Similarly, four pattern analyses were carried out: first-order one-factor analysis, first-order two-factor uncorrelated analysis, first-order two-factor correlated analysis, and second-order factor analysis. Figure 4 shows the second-order plane model for WeMedia ads marketing evaluation based on the demand of Internet economy.

\section{Model Verification and Results Analysis}

The correctness of the three effect evaluation models was evaluated by a fitness test. The test results on online marketing performance evaluation model are listed in Table 4. The second-order factor analysis had the lowest $\chi^{2}$, DOF, and $\chi^{2} / \mathrm{DOF}(67.352,51,1.402)$. Hence, a second-order plane is suitable for the evaluation of online marketing performance.

The fitness test results on the supplier performance evaluation model are listed in Table 5. Second-order factor analysis and first-order three-factor correlated analysis had consistent fitness in terms of DOF and $\chi^{2} / \mathrm{DOF}$. That is, when the model plane only has three latent variables, namely, supplier sales performance, sale service, and consumer source concentration, the two models have the same fitness (25 and 1.739). However, the second-order factor analysis achieved the minimum $\chi^{2}$. Therefore, the secondorder plane is the most suitable for the evaluation of supplier performance.

The fitness test results on the relationship benefit evaluation model are listed in Table 6. Second-order factor analysis and first-order two-factor correlated analysis had consistent fitness in terms of DOF and $\chi^{2} / \mathrm{DOF}$. That is, when the model plane only has two latent variables, namely, consumer relationship benefit and enterprise participation, the two models have the same fitness (26 and 1.786). However, the second-order factor analysis achieved the minimum $\chi^{2}$ (42.187). Therefore, the second-order plane is the most suitable for the evaluation of relationship benefit.

Table 7 shows the results of parameter estimation and convergent validity for the online marketing performance 
TABLE 1: Descriptions and statistics of online marketing performance ratings.

\begin{tabular}{|c|c|c|c|c|c|c|c|c|c|}
\hline Item & $\begin{array}{l}\text { Strongly } \\
\text { disagree }\end{array}$ & $\begin{array}{c}\text { Moderately } \\
\text { disagree }\end{array}$ & $\begin{array}{l}\text { Slightly } \\
\text { disagree }\end{array}$ & Neutral & $\begin{array}{c}\text { Slightly } \\
\text { agree }\end{array}$ & $\begin{array}{l}\text { Moderately } \\
\text { agree }\end{array}$ & $\begin{array}{l}\text { Strongly } \\
\text { agree }\end{array}$ & Mean & $\begin{array}{l}\text { Standard } \\
\text { deviation }\end{array}$ \\
\hline$M P_{111}$ & 0 & 1 & 9 & 20 & 102 & 62 & 31 & 5.372 & 1.005 \\
\hline$M P_{112}$ & 1 & 0 & 8 & 35 & 98 & 59 & 42 & 5.492 & 0.958 \\
\hline$M P_{113}$ & 1 & 2 & 10 & 34 & 72 & 72 & 31 & 5.435 & 1.032 \\
\hline$M P_{114}$ & 0 & 1 & 12 & 32 & 105 & 62 & 26 & 5.192 & 1.005 \\
\hline$M P_{121}$ & 1 & 1 & 0 & 22 & 85 & 54 & 18 & 5.031 & 1.063 \\
\hline$M P_{122}$ & 1 & 3 & 0 & 35 & 91 & 66 & 16 & 5.128 & 0.942 \\
\hline$M P_{123}$ & 1 & 2 & 2 & 56 & 107 & 59 & 27 & 5.295 & 1.034 \\
\hline
\end{tabular}

TABLE 2: Descriptions and statistics of supplier performance.

\begin{tabular}{|c|c|c|c|c|c|c|c|c|c|}
\hline Item & $\begin{array}{l}\text { Strongly } \\
\text { disagree }\end{array}$ & $\begin{array}{c}\text { Moderately } \\
\text { disagree }\end{array}$ & $\begin{array}{l}\text { Slightly } \\
\text { disagree }\end{array}$ & Neutral & $\begin{array}{l}\text { Slightly } \\
\text { agree }\end{array}$ & $\begin{array}{c}\text { Moderately } \\
\text { agree }\end{array}$ & $\begin{array}{c}\text { Strongly } \\
\text { agree }\end{array}$ & Mean & $\begin{array}{l}\text { Standard } \\
\text { deviation }\end{array}$ \\
\hline$M P_{211}$ & 3 & 2 & 9 & 67 & 85 & 31 & 19 & 4.756 & 1.075 \\
\hline$M P_{212}$ & 5 & 2 & 8 & 91 & 44 & 45 & 25 & 4.821 & 1.132 \\
\hline$M P_{213}$ & 2 & 3 & 10 & 87 & 37 & 37 & 26 & 4.937 & 1.116 \\
\hline$M P_{214}$ & 9 & 37 & 12 & 56 & 27 & 26 & 12 & 3.923 & 1.533 \\
\hline$M P_{221}$ & 13 & 40 & 43 & 53 & 32 & 31 & 13 & 3.964 & 1.579 \\
\hline$M P_{222}$ & 27 & 35 & 45 & 37 & 25 & 25 & 5 & 3.415 & 1.572 \\
\hline$M P_{223}$ & 0 & 3 & 48 & 85 & 54 & 48 & 59 & 5.237 & 1.139 \\
\hline$M P_{231}$ & 1 & 2 & 5 & 86 & 46 & 51 & 47 & 5.621 & 1.183 \\
\hline$M P_{232}$ & 2 & 0 & 2 & 83 & 37 & 37 & 43 & 5.325 & 1.156 \\
\hline$M P_{233}$ & 1 & 7 & 8 & 78 & 103 & 42 & 25 & 4.998 & 0.992 \\
\hline$M P_{234}$ & 1 & 2 & 8 & 39 & 94 & 58 & 22 & 5.135 & 1.056 \\
\hline
\end{tabular}

Table 3: Descriptions and statistics of relationship benefit.

\begin{tabular}{|c|c|c|c|c|c|c|c|c|c|}
\hline Item & $\begin{array}{l}\text { Strongly } \\
\text { disagree }\end{array}$ & $\begin{array}{c}\text { Moderately } \\
\text { disagree }\end{array}$ & $\begin{array}{l}\text { Slightly } \\
\text { disagree }\end{array}$ & Neutral & $\begin{array}{c}\text { Slightly } \\
\text { agree }\end{array}$ & $\begin{array}{l}\text { Moderately } \\
\text { agree }\end{array}$ & $\begin{array}{l}\text { Strongly } \\
\text { agree }\end{array}$ & Mean & $\begin{array}{l}\text { Standard } \\
\text { deviation }\end{array}$ \\
\hline$M P_{311}$ & 1 & 12 & 25 & 27 & 103 & 45 & 13 & 4.756 & 1.195 \\
\hline$M P_{312}$ & 3 & 4 & 17 & 65 & 85 & 42 & 8 & 4.723 & 1.139 \\
\hline$M P_{313}$ & 5 & 3 & 8 & 26 & 76 & 65 & 56 & 5.532 & 1.216 \\
\hline$M P_{314}$ & 2 & 6 & 15 & 53 & 85 & 37 & 25 & 4.879 & 1.293 \\
\hline$M P_{321}$ & 1 & 2 & 16 & 46 & 109 & 42 & 13 & 4.921 & 1.031 \\
\hline$M P_{322}$ & 1 & 0 & 2 & 35 & 108 & 37 & 16 & 4.859 & 1.143 \\
\hline
\end{tabular}

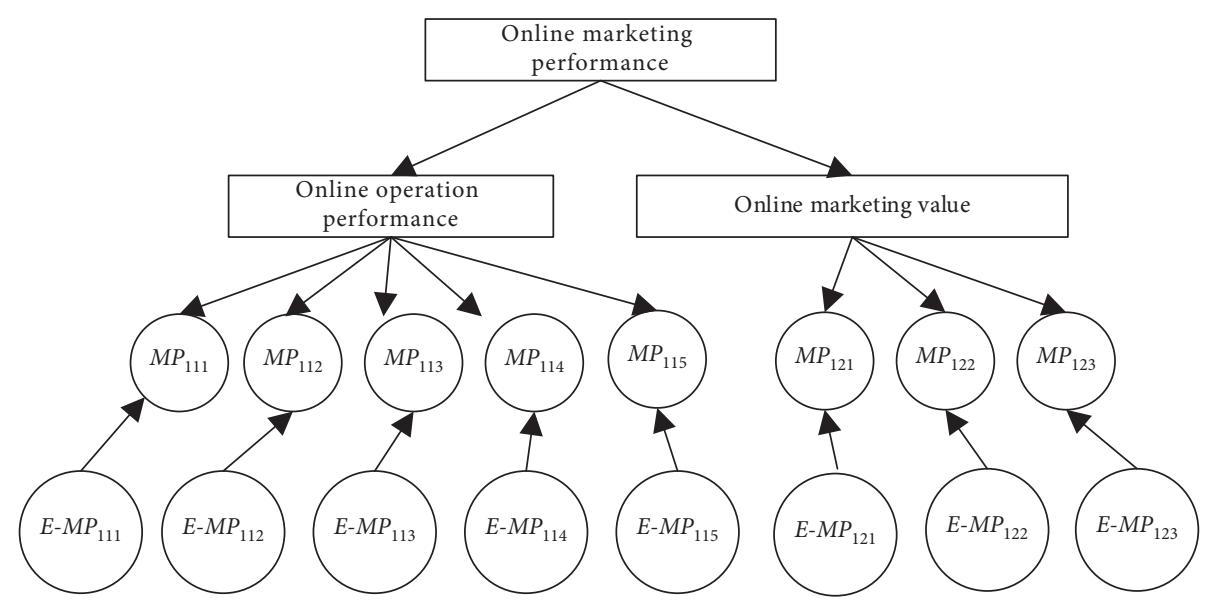

FIgURE 1: Second-order plane model for online marketing performance evaluation. 


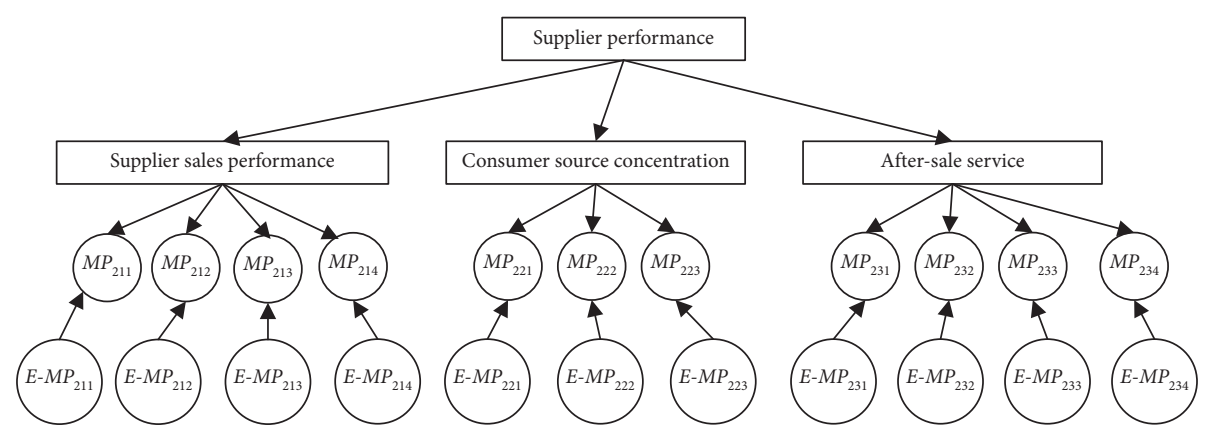

FIGURE 2: Second-order plane model for supplier performance evaluation.

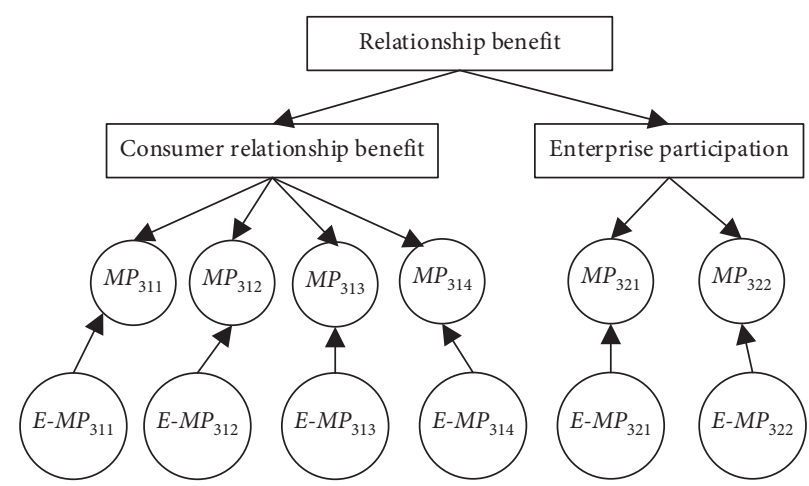

Figure 3: Second-order plane model for relationship benefit.

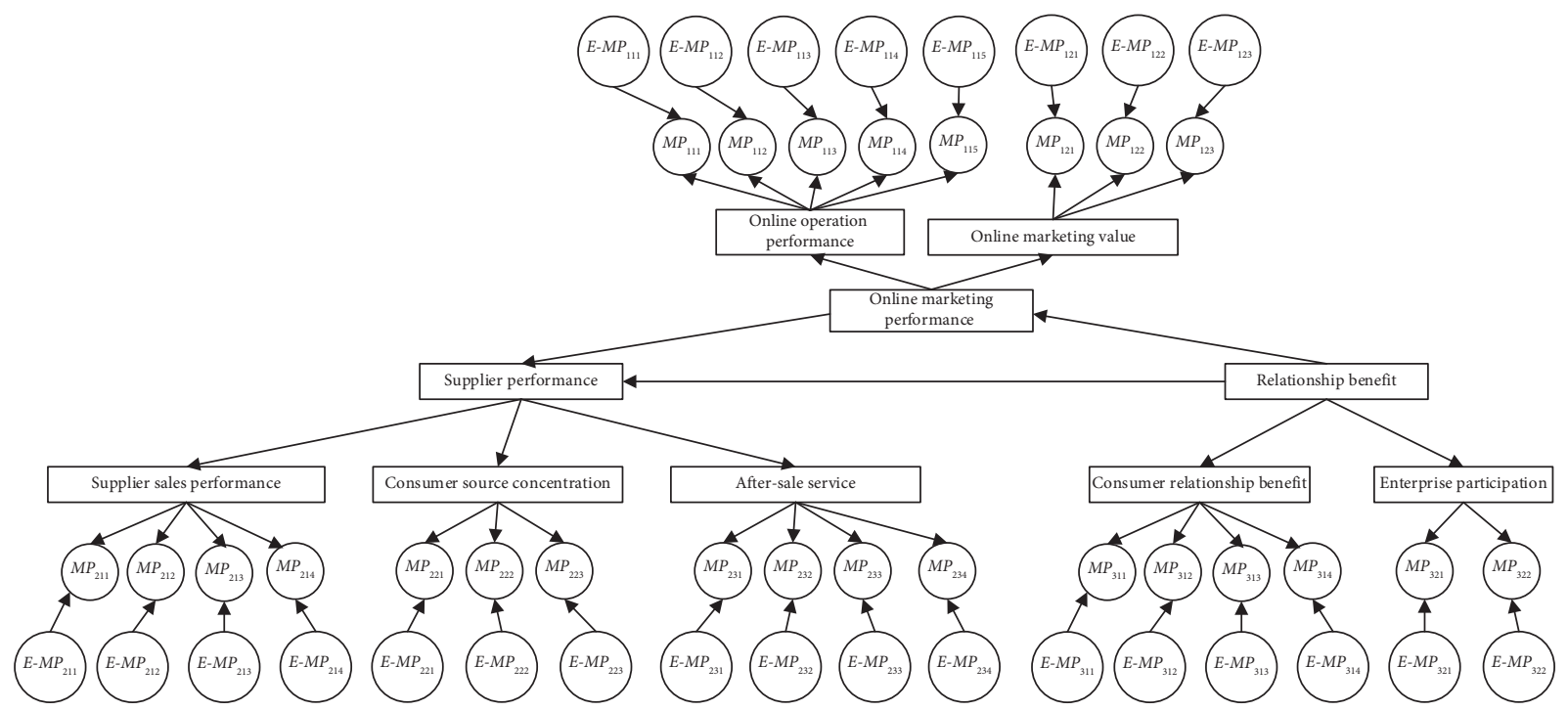

FIGURE 4: Second-order plane model for WeMedia ads marketing evaluation.

evaluation model. Through second-order CFA, the composite reliabilities of the planes of this model were all between 0.7 and 0.95 , and their SRMSSARs were all greater than zero. Therefore, the model makes no offending estimate. The AVEs of the two planes were both larger than 0.5, meeting the required standard convergent validity. This further confirms that the overall fitness of the online marketing performance evaluation model is acceptable.
Table 8 shows the results of parameter estimation and convergent validity for the supplier performance evaluation model. The composite reliabilities of the three planes of this model were all between 0.9 and 0.95 , and their SRMSSARs were all greater than zero. Therefore, the model makes no offending estimate. The AVEs of the three planes were all larger than 0.7 , meeting the requirements for standard convergent validity and fitness. 
TABLE 4: Fitness of online marketing performance evaluation.

\begin{tabular}{|c|c|c|c|c|c|c|c|}
\hline $\begin{array}{l}\text { Test models for online } \\
\text { marketing performance } \\
\text { evaluation }\end{array}$ & $\begin{array}{l}\text { Chi-square } \\
\quad\left(\chi^{2}\right)\end{array}$ & $\begin{array}{l}\text { Degree of } \\
\text { freedom } \\
(\mathrm{DOF})\end{array}$ & $\begin{array}{c}\chi^{2} / \\
\mathrm{DOF}\end{array}$ & $\begin{array}{l}\text { Goodness of } \\
\text { fit index (GFI) }\end{array}$ & $\begin{array}{c}\text { Adjusted } \\
\text { GFI (AGFI) }\end{array}$ & $\begin{array}{l}\text { Comparative fit } \\
\text { index (CFI) }\end{array}$ & $\begin{array}{c}\text { Root mean square error } \\
\text { of approximation } \\
\text { (RMSEA) }\end{array}$ \\
\hline Null model & 1435.235 & 65 & 21.637 & 0.358 & 0.163 & 0 & 0.439 \\
\hline $\begin{array}{l}\text { First-order one-factor } \\
\text { analysis }\end{array}$ & 285.351 & 56 & 5.352 & 0.562 & 0.274 & 0.532 & 0.347 \\
\hline $\begin{array}{l}\text { First-order two-factor } \\
\text { uncorrelated analysis }\end{array}$ & 407.429 & 52 & 7.593 & 0.867 & 0.738 & 0.955 & 0.156 \\
\hline $\begin{array}{l}\text { First-order two-factor } \\
\text { correlated analysis }\end{array}$ & 67.539 & 57 & 1.433 & 0.948 & 0.962 & 0.975 & 0.053 \\
\hline $\begin{array}{l}\text { Second-order factor } \\
\text { analysis }\end{array}$ & 67.352 & 51 & 1.402 & 0.948 & 0.962 & 0.975 & 0.053 \\
\hline Recommendation & $\begin{array}{l}\text { The } \\
\text { smaller, the } \\
\text { better. }\end{array}$ & $\begin{array}{l}\text { The greater, } \\
\text { the better. }\end{array}$ & $<5$ & $>0.9$ & $>0.9$ & $>0.7$ & $<0.06$ \\
\hline
\end{tabular}

TABLE 5: Fitness of supplier performance evaluation.

\begin{tabular}{|c|c|c|c|c|c|c|c|}
\hline Test models for supplier performance evaluation & $\chi^{2}$ & DOF & $\begin{array}{c}\chi^{2} / \\
\text { DOF }\end{array}$ & GFI & AGFI & CFI & RMSEA \\
\hline Null model & 1531.394 & 35 & 43.257 & 0.359 & 0.162 & 0 & 0.452 \\
\hline First-order one-factor analysis & 753.265 & 29 & 29.392 & 0.592 & 0.297 & 0.543 & 0.345 \\
\hline First-order three-factor uncorrelated analysis & 157.937 & 29 & 6.008 & 0.857 & 0.735 & 0.937 & 0.152 \\
\hline First-order three-factor correlated analysis & 39.396 & 25 & 1.739 & 0.931 & 0.936 & 0.971 & 0.056 \\
\hline Second-order factor analysis & 38.354 & 25 & 1.739 & 0.931 & 0.936 & 0.971 & 0.056 \\
\hline Recommendation & The smaller, the better. & The greater, the better. & $<5$ & $>0.9$ & $>0.9$ & $>0.7$ & $<0.06$ \\
\hline
\end{tabular}

TABLE 6: Fitness of relationship benefit fitness.

\begin{tabular}{|c|c|c|c|c|c|c|c|}
\hline Test models for relationship benefit & $x^{2}$ & DOF & $\chi^{2} / \mathrm{DOF}$ & GFI & AGFI & CFI & RMSEA \\
\hline Null model & 1572.954 & 34 & 44.124 & 0.351 & 0.167 & 0 & 0.433 \\
\hline rder one-factor analysis & 731.24 & 28 & 28.122 & 0.585 & 0.217 & 0.567 & 0.322 \\
\hline First-order two-factor uncorrelated analysis & 167.19 & 29 & 6.014 & 0.874 & 0.752 & 0.984 & 0.154 \\
\hline First-order two-factor correlated analysis & 44.15 & 26 & 1.786 & 0.943 & 0.941 & 0.976 & 0.062 \\
\hline analysis & 42.187 & 26 & 1.786 & 0.943 & 0.941 & 0.976 & 0.062 \\
\hline Recommendation & The smaller, the better. & The greater, the better. & $<5$ & $>0.9$ & $>0.8$ & $>0.9$ & $<0.07$ \\
\hline
\end{tabular}

TABLE 7: Test results on online marketing performance evaluation model.

\begin{tabular}{|c|c|c|c|c|c|c|}
\hline \multirow[b]{2}{*}{ Index } & \multicolumn{2}{|c|}{ Parameter estimation } & \multicolumn{4}{|c|}{ Convergent validity } \\
\hline & $\begin{array}{l}\text { Nonstandardized } \\
\text { factor loading }\end{array}$ & $\begin{array}{l}\text { Square root of mean sum of } \\
\text { square for approximate } \\
\text { residuals (SRMSSAR) }\end{array}$ & $\begin{array}{l}\text { Standardized } \\
\text { factor loading }\end{array}$ & $\begin{array}{c}\text { Square of } \\
\text { multivariate } \\
\text { correlation } \\
\text { coefficient }\end{array}$ & $\begin{array}{l}\text { Composite } \\
\text { reliability }\end{array}$ & $\begin{array}{c}\text { Average } \\
\text { variance } \\
\text { extracted (AVE) }\end{array}$ \\
\hline$M P_{111}$ & 0.892 & 0.095 & 0.635 & 0.452 & & \\
\hline$M P_{112}$ & 0.965 & 0.092 & 0.782 & 0.633 & & \\
\hline$M P_{113}$ & 1 & & 0.765 & 0.515 & 0.782 & 0.551 \\
\hline$M P_{114}$ & 0.831 & 0.075 & 0.672 & 0.446 & & \\
\hline$M P_{121}$ & 1.052 & 0.082 & 0.803 & 0.649 & & \\
\hline$M P_{122}$ & 1 & & 0.805 & 0.657 & 0.832 & 0.571 \\
\hline$M P_{123}$ & 0.835 & 0.063 & 0.741 & 0.578 & & \\
\hline
\end{tabular}

Table 9 shows the results of parameter estimation and convergent validity for the relationship benefit evaluation model. Through second-order CFA, the composite reliabilities of the six latent variables (evaluation criteria) were all between 0.75 and 0.95 , and their SRMSSARs were all greater than zero. The AVEs of the two planes were all larger than 0.5 . Therefore, the model makes no offending estimate and meet the requirements on fitness.

Finally, the error variances of the overall second-order plane model for WeMedia ads marketing evaluation were 
TABLE 8: Test results on supplier performance evaluation model.

\begin{tabular}{|c|c|c|c|c|c|c|}
\hline \multirow[b]{2}{*}{ Index } & \multicolumn{2}{|c|}{ Parameter estimation } & \multicolumn{4}{|c|}{ Convergent validity } \\
\hline & $\begin{array}{c}\text { Nonstandardized factor } \\
\text { loading }\end{array}$ & SRMSSAR & $\begin{array}{l}\text { Standardized factor } \\
\text { loading }\end{array}$ & $\begin{array}{c}\text { Square of multivariate correlation } \\
\text { coefficient }\end{array}$ & $\begin{array}{l}\text { Composite } \\
\text { reliability }\end{array}$ & AVE \\
\hline$M P_{211}$ & 1 & & 0.752 & 0.532 & & \\
\hline$M P_{212}$ & 1.235 & 0.095 & 0.945 & 0.891 & 0923 & 0751 \\
\hline$M P_{213}$ & 1.224 & 0.092 & 0.914 & 0.835 & 0.923 & 0.751 \\
\hline$M P_{214}$ & 1 & & 0.892 & 0.864 & & \\
\hline$M P_{221}$ & 1.082 & 0.053 & 0.913 & 0.632 & & \\
\hline$M P_{222}$ & 0.935 & 0.052 & 0.796 & 0.735 & 0.905 & 0.765 \\
\hline$M P_{223}$ & 1 & & 0.871 & 0.915 & & \\
\hline$M P_{231}$ & 1.037 & 0.063 & 0.954 & 0.736 & & \\
\hline$M P_{232}$ & 0.934 & 0.045 & 0.802 & 0.632 & 0.023 & 0752 \\
\hline$M P_{233}$ & 1.03 & 0.115 & 0.735 & 0.532 & 0.923 & 0.152 \\
\hline$M P_{234}$ & 0.996 & 0.112 & 0.765 & 0.571 & & \\
\hline
\end{tabular}

TABle 9: Test results on relationship benefit evaluation model.

\begin{tabular}{|c|c|c|c|c|c|c|}
\hline \multirow[b]{2}{*}{ Index } & \multicolumn{2}{|c|}{ Parameter estimation } & \multicolumn{4}{|c|}{ Convergent validity } \\
\hline & $\begin{array}{c}\text { Nonstandardized factor } \\
\text { loading }\end{array}$ & SRMSSAR & $\begin{array}{l}\text { Standardized factor } \\
\text { loading }\end{array}$ & $\begin{array}{c}\text { Square of multivariate correlation } \\
\text { coefficient }\end{array}$ & $\begin{array}{l}\text { Composite } \\
\text { reliability }\end{array}$ & AVE \\
\hline$M P_{311}$ & 1 & & 0.593 & 0.352 & & \\
\hline$M P_{312}$ & 1.372 & 0.153 & 0.635 & 0.451 & 0792 & 0.535 \\
\hline$M P_{313}$ & 1.284 & 0.166 & 0.732 & 0.516 & 0.192 & 0.550 \\
\hline$M P_{314}$ & 1.125 & 0.152 & 0.674 & 0.432 & & \\
\hline$M P_{321}$ & 1.075 & 0.14 & 0.631 & 0.458 & & 0.531 \\
\hline$M P_{322}$ & 1.043 & 0.13 & 0.622 & 0.471 & 0.762 & 0.531 \\
\hline
\end{tabular}

TABLE 10: Estimated error variance.

\begin{tabular}{|c|c|c|c|c|c|c|c|}
\hline Variable & Estimated error variance & SRMSSAR & Composite reliability & Variable & Estimated error variance & SRMSSAR & $\begin{array}{l}\text { Composite } \\
\text { reliability }\end{array}$ \\
\hline$E-M P_{111}$ & 0.372 & 0.075 & 4.621 & $E-M P_{222}$ & 0.351 & 0.049 & 7.468 \\
\hline$E-M P_{112}$ & 0.267 & 0.062 & 4.195 & $E-M P_{223}$ & 0.307 & 0.053 & 7.531 \\
\hline$E-M P_{113}$ & 0.205 & 0.047 & 4.152 & $E-M P_{231}$ & 0.652 & 0.077 & 8.705 \\
\hline$E-M P_{114}$ & 0.273 & 0.051 & 5.709 & $E-M P_{232}$ & 0.243 & 0.065 & 4.138 \\
\hline$E-M P_{121}$ & 0.231 & 0.035 & 4.067 & $E-M P_{233}$ & 0.317 & 0.046 & 5.729 \\
\hline$E-M P_{122}$ & 0.107 & 0.032 & 3.215 & $E-M P_{234}$ & 0.802 & 0.098 & 9.035 \\
\hline$E-M P_{123}$ & 0.112 & 0.152 & 4.812 & $E-M P_{311}$ & 0.527 & 0.041 & 7.421 \\
\hline$E-M P_{211}$ & 0.253 & 0.095 & 6.827 & $E-M P_{312}$ & 0.103 & 0.036 & 3.219 \\
\hline$E-M P_{212}$ & 1.072 & 0.092 & 7.136 & $E-M P_{313}$ & 0.114 & 0.158 & 4.814 \\
\hline$E-M P_{213}$ & 0.624 & 0.035 & 6.531 & $E-M P_{314}$ & 0.981 & 0.105 & 9.732 \\
\hline$E-M P_{214}$ & 0.329 & 0.068 & 8.759 & $E-M P_{321}$ & 0.863 & 0.089 & 9.187 \\
\hline$E-M P_{221}$ & 1.013 & 0.056 & 7.127 & $E-M P_{322}$ & 0.325 & 0.027 & 5.759 \\
\hline$E-M P_{11}$ & 0.309 & 0.093 & 3.135 & $E-M P_{31}$ & 0.437 & 0.053 & 5.706 \\
\hline$E-M P_{12}$ & 0.862 & 0.098 & 7.112 & $E-M P_{32}$ & 0.425 & 0.089 & 8.579 \\
\hline$E-M P_{21}$ & 0.472 & 0.057 & 8.831 & $E-M P_{1}$ & 0.726 & 0.081 & 8.572 \\
\hline$E-M P_{22}$ & 0.175 & 0.032 & 9.156 & $E-M P_{2}$ & 0.518 & 0.062 & 7.351 \\
\hline$E-M P_{23}$ & 0.493 & 0.058 & 5.831 & $E-M P_{3}$ & 0.467 & 0.048 & 9.514 \\
\hline
\end{tabular}


counted (Table 10) to see if the evaluation indices oscillate in the specified ranges. The minimum error variances were all positive. $E-M P_{221}$ and $E-M P_{212}$ were the only errors with significant variances under the level of 0.005 . The variances of all the other errors were significant at the level of 0.001 , which meet the statistical requirements on offending estimates.

\section{Conclusions}

This paper explores the evaluation of WeMedia ads marketing under the demand of Internet economy. Specifically, a three-dimensional EIS was established for WeMedia ads marketing, covering such aspects as online marketing performance, supplier performance, and relationship benefit. Then, multilevel FCE was performed to determine the weights of all indices. Then, effect evaluation models were constructed and subjected to CFAs. Finally, descriptive statistics were analyzed to judge whether the index samples are sufficiently diverse. The fitness, parameter estimations, convergence validities of the three models were obtained through experiments. The authors tested whether the composite reliabilities of the planes of each model are all between 0.7 and 0.95 , and their SRMSSARs are all greater than zero. Finally, the error variances were estimated, which confirm that the proposed model makes no offending estimate and meets the fitness requirement.

\section{Data Availability}

The data used to support the findings of this study are available from the corresponding author upon request.

\section{Conflicts of Interest}

The authors declare that they have no conflicts of interest regarding the publication of this paper.

\section{Acknowledgments}

This paper was supported by the Research and Inheritance of Daur Traditional Arts and Crafts (Project Director), Humanities and Social Sciences Project, Department of Education, Heilongjiang Province, China (12542021), and Digital Culture Protection of Daur Papercutting (Project Director), Leading Group of Arts and Science Planning, Department of Culture, Heilongiiang Province, China (2015D084).

\section{References}

[1] Z. Chen, H. Lu, and L. Li, "How new media marketing influence consumers' purchase behavior in the era of big data,"vol. 1, pp. 601-606, in Proceedings of the in Cyber Security Intelligence and Analytics: 2021 International Conference on Cyber Security Intelligence and Analytics (CSIA2021), vol. 1, , Springer, Shenyang, China, March 2021.

[2] H. Wu, L. Liu, X. Zhang, and H. Ma, "Vbargain: a marketdriven quality oriented incentive for mobile video offloading," IEEE Transactions on Mobile Computing, vol. 18, no. 9, pp. 2203-2216, 2017.
[3] C. Tay, "Comparison of the impact of information and communication technology between bilateral trade in goods and services," Journal of System and Management Sciences, vol. 10, no. 1, pp. 1-31, 2020.

[4] N. Deepika and M. N. Bhat, "Predicting the e-commerce companies stock with the aid of web advertising via search engine and social media," Revue d'Intelligence Artificielle, vol. 34, no. 1, pp. 89-94, 2020.

[5] J. Dhar and A. K. Jodder, "An effective recommendation system to forecast the best educational program using machine learning classification algorithms," Ingénierie des systèmes d information, vol. 25, no. 5, pp. 559-568, 2020.

[6] X. Bai, "A hierarchical model of e-commerce sellers based on data mining," Ingénierie des systèmes d information, vol. 25, no. 1, pp. 119-125, 2020.

[7] J. Narkbuakaew, W. Chantatub, and S. Unahanandh, “A conceptual model of factors affecting popularity of marketing videos on video sharing sites," in Proceedings of the International Conference on Electronic Business (ICEB), pp. 10-16, Hong Kong, China, January 2015.

[8] K. Goodrich, S. Schiller, and D. Galletta, "Intrusiveness of online video advertising and its effects on marketing outcomes," in Proceedings of the International Conference on Information Systems, vol. 1, pp. 83-92, Shanghai, China, December 2011.

[9] L. M. Wendt, J. Griesbaum, and R. Kölle, "Product advertising and viral stealth marketing in online videos," Aslib Journal of Information Management, vol. 68, no. 3, pp. 250-264, 2016.

[10] M. Yeum, K. Wee, and W. Bang, "“'The effect of internal marketing on competitive advantage as organizational coaching - the mediating effect of service innovation," Journal of System and Management Sciences, vol. 10, no. 1, pp. 62-71, 2020.

[11] H. Pan, "Network video-the new direction of film market development," in Prceedings of the in 2020 16th Dahe Fortune China Forum and Chinese High-educational Management Annual Academic Conference (DFHMC), pp. 5-10, Zhengzhou, China, December 2020.

[12] G. HimaBindu, C. Anuradha, and P. Murty, "Assessment of combined shape, color and textural features for video duplication," Traitement du Signal, vol. 36, no. 2, pp. 193-199, 2019.

[13] J. Ram and D. Xu, "Live streaming video e-commerce: examining the operational strategies," Journal Européen des Systèmes Automatisés, vol. 52, no. 1, pp. 1-9, 2019.

[14] S. Kang and H. Choi, "Motive and attitude to use QR code as an advertising and publicity media: an empirical study," Journal of System and Management Sciences, vol. 9, no. 4, pp. 111-126, 2019.

[15] U. Claude, "Predicting tourism demands by google trends: a hidden markov models based study," Journal of System and Management Sciences, vol. 10, no. 1, pp. 106-120, 2020.

[16] M. Lei and L. Li, "Study on the framework of enterprise new media marketing strategy based on internet plus background," Boletin Tecnico/Technical Bulletin, vol. 55, no. 18, pp. 79-85, 2017.

[17] H. Wang, "An effect analysis model for corporate marketing mix based on artificial neural network," Ingénierie des Systèmes d Information, vol. 25, no. 5, pp. 579-587, 2020.

[18] F. Kollintza-Kyriakoulia, M. Maragoudakis, and A. Krithara, "Measuring the impact of financial news and social media on stock market modeling using time series mining techniques," Algorithms, vol. 11, no. 11, p. 181, 2018. 
[19] S. M. Kim, "How can we make a socially optimal large-scale media platform? analysis of a monopolistic internet media platform using two-sided market theory," Telecommunications Policy, vol. 40, no. 9, pp. 899-918, 2016.

[20] A. Wang and X. Gao, "Hybrid variable-scale clustering method for social media marketing on user generated instant music video," Tehnički Vjesnik, vol. 26, no. 3, pp. 771-777, 2019.

[21] H. Yas, A. Jusoha, D. Streimikieneb, A. Mardania et al., "The negative role of social media during the COVID-19 outbreak," International Journal of Sustainable Development and Planning, vol. 16, no. 2, pp. 219-228, 2021.

[22] U. Ferraro-Petrillo, "Using the audio of 8-bit video games to monitor web marketing campaigns," Multimedia Systems, vol. 23, no. 4, pp. 469-484, 2017.

[23] K. Revett, S. T. De Magalhães, M. J. Magalhães, and H. Jahankhani, "Balancing targeted delivery of content and personal freedom in the digital on-line video marketing landscape," in Proceedings of the in International Conference on Global Security, Safety, and Sustainability, pp. 96-105, Springer, London, UK, January 2017.

[24] R. Panchagnula, A. Kumar Bajpai, S. Agrawal, and Y. Ashokraj, "Dissolution testing of marketed rifampicin containing fixed dose combination formulations using a new discriminative media: a post marketing retrospective study," Die Pharmazie, vol. 61, no. 10, pp. 851-854, 2006.

[25] Q. Liu, "Analysis of short video marketing strategy under the background of social e-commerce," in Proceedings of the in 2021 2nd International Conference on E-Commerce and Internet Technology (ECIT), pp. 20-25, Hangzhou, China, March 2021.

[26] C. Xiao, Y. Zhu, D. Hu, and Z. Xie, "The impact of tik tok video marketing on tourist destination image cognition and tourism intention," in Proceedings of the in 2020 International Workshop on Electronic Communication and Artificial Intelligence (IWECAI), pp. 116-119, Shanghai, China, June 2020.

[27] G. Chen, L. He, and K. Papangelis, "Sentimental analysis of Chinese new social media for stock market information," in Proceedings of the 2019 the International Conference on Pattern Recognition and Artificial Intelligence, pp. 1-6, Wenzhou, China, August 2019.

[28] K. A. Brekke and T. Nilssen, "Media competition enhances new-product entry: on the market for fake observations," Information Economics and Policy, vol. 31, pp. 59-66, 2015.

[29] M. Mujahid, Y. Haskas, M. Hamid, I. Safar, and A. S. Arief, "Linking green marketing with performance: environmental marketing model for small business," IOP Conference Series: Earth and Environmental Science, vol. 737, no. 1, Article ID 012024, 2021.

[30] Y. Lyu, X. Yang, and J. Yao, "Comprehensive evaluation and analysis of teaching and research performance of art majors," International Journal of Emerging Technologies in Learning (iJET), vol. 15, no. 20, pp. 241-254, 2020.

[31] W. Wu, W. Liu, F. N. Zhang, and V. Dixit, "A new flexible parking reservation scheme for the morning commute under limited parking supplies," Networks and Spatial Economics, in press, 2021.

[32] S. Wang and X. Lu, “"Design and application of an evaluation index system for urban development quality of China's subprovincial cities in the new era," International Journal of Sustainable Development and Planning, vol. 15, no. 3, pp. 327-334, 2020.

[33] S. Wang and W. Wei, "Comprehensive evaluation on environmental impact of green buildings considering sustainable development," International Journal of Design \& Nature and Ecodynamics, vol. 15, no. 3, pp. 449-453, 2020.

[34] N. N. Hien and P. H. Chi, "The factors affecting household electricity saving behavior: a study in Vietnam," International Journal of Sustainable Development and Planning, vol. 15, no. 8, pp. 1241-1250, 2020.

[35] K. Han, "Evaluation of teaching quality of college physical education based on analytic hierarchy process," International Journal of Emerging Technologies in Learning (iJET), vol. 15, no. 10, pp. 86-99, 2020.

[36] C. Bensaci, Y. Zennir, D. Pomorski, F. Innal, and Y. Liu, "Distributed vs. hybrid control architecture using STPA and AHP-application to an autonomous mobile multi-robot system," International Journal of Safety and Security Engineering, vol. 11, no. 1, pp. 1-12, 2021. 